\title{
Qualidade de luz na multiplicação e enraizamento in vitro de mirtileiro 'Woodard'
}

\author{
Light quality on in vitro multiplication and rooting of 'Woodard' blueberry \\ Calidad de luz en la multiplicación y enraizamiento in vitro de arándanos 'Woodard'
}

Recebido: 09/02/2021 | Revisado: 14/02/2021 | Aceito: 16/02/2021 | Publicado: 25/02/2021

\author{
Jéssica Gonsalez Cruz \\ ORCID: https://orcid.org/0000-0001-5805-8449 \\ Universidade Federal de Pelotas, Brasil \\ E-mail: jessica.gonsalez@hotmail.com \\ Mateus da Silveira Pasa \\ ORCID: https://orcid.org/0000-0003-0481-0206 \\ Universidade Federal de Pelotas, Brasil \\ E-mail: mateus.pasa@gmail.com \\ Camila Schwartz Dias \\ ORCID: https://orcid.org/0000-0002-0061-7874 \\ Universidade Federal de Pelotas, Brasil \\ E-mail: camilaschdias@hotmail.com \\ Flávia Loy \\ ORCID: https://orcid.org/0000-0003-3253-5723 \\ Faculdade Unyleya, Brasil \\ E-mail: flavia_loy@yahoo.com.br \\ Andrio Spiller Copatti \\ ORCID: https://orcid.org/0000-0002-4789-7818 \\ Universidade Federal de Pelotas, Brasil \\ E-mail: andriocopatti@gmail.com \\ Laura Reisdörfer Sommer \\ ORCID: https://orcid.org/0000-0002-7735-8188 \\ Universidade Regional Integrada do Alto Uruguai e das Missões, Brasil \\ E-mail: laurasommer@san.uri.br \\ Sidnei Deuner \\ ORCID: https://orcid.org/0000-0003-3131-1867 \\ Universidade Federal de Pelotas, Brasil \\ E-mail: sdeuner@yahoo.com.br \\ Paulo Celso de Mello-Farias \\ ORCID: https://orcid.org/0000-0002-6519-4972 \\ Universidade Federal de Pelotas, Brasil \\ E-mail: mellofarias@yahoo.com.br
}

\section{Resumo}

O objetivo deste estudo foi avaliar o efeito da qualidade da luz e dos reguladores de crescimento 2-isopentenil adenina (2-ip) e ácido indol 3-butírico (AIB) na multiplicação in vitro e enraizamento do mirtilo 'Woodard'. Os experimentos foram organizados em um delineamento inteiramente casualizado, com três níveis de qualidade de luz (vermelho, azul e branco) e dois níveis de regulador de crescimento vegetal (presença ou ausência de 100 mg L-1 2-ip ou 0,5 mg L-1 AIB, nos experimentos de multiplicação e enraizamento, respectivamente). Os parâmetros avaliados em ambos os experimentos foram taxa de sobrevivência (\%), número de brotos por explante, comprimento dos brotos (cm); número de folhas por explante e área foliar $(\mathrm{cm} 2)$. No experimento de multiplicação também foi quantificado o conteúdo de pigmentos fotossintéticos [clorofila (chl) a e chl b, chl a + b, e carotenóides] e no ensaio de enraizamento o número e comprimento da raiz. Os resultados mostram que a presença de 2 -ip em associação com a luz branca resulta em brotações mais longas, bem como em maior número de brotos e folhas. A maior área foliar foi observada com luz branca. O número e o comprimento da raiz foram maiores na presença de AIB no meio. A associação de luz fluorescente branca e a presença de 2-isopentenil adenina (2-ip) ou ácido indol 3-butírico (AIB) no meio fornece os melhores resultados para multiplicação in vitro e enraizamento, respectivamente, de 'Woodard' mirtilo.

Palavras-chave: Micropropagação; Vaccinium spp.; Filtros de acetato de celulose; Reguladores de crescimento vegetal.

\section{Abstract}

The objective of this study was to evaluate the effect of light quality and the plant growth regulators 2-isopentenyl adenine (2-ip) and indol 3-butyric acid (IBA) on in vitro multiplication and rooting of 'Woodard' blueberry. The experiments were arranged in a completely randomized design, with three light quality levels (red, blue, and white), and two plant growth regulator levels (presence or absence of either $100 \mathrm{mg} \mathrm{L}-12$-ip or $0.5 \mathrm{mg}$ L-1 IBA, in the 
multiplication and rooting experiments, respectively). The parameters assessed in both experiments were survival rate $(\%)$, number of shoots per explants shoot length $(\mathrm{cm})$; number of leaves per explant, and leaf area $(\mathrm{cm} 2)$. In the multiplication experiment was also quantified the photosynthetic pigments contents [chlorophyll (chl) a and chl b, chl $\mathrm{a}+\mathrm{b}$, and carotenoids] and in the rooting trial the root number and length. The results show that the presence of 2 -ip in association with white light results in longer shoots, as well as greater number of shoots and leaves. The greastest leaf area was observed with white light. Root number and length was greater in the presence of IBA in the medium. The association of white fluorescent light and the presence of either 2-isopentenyl adenine (2-ip) or indole 3-butyric acid (IBA) in the medium, provides the best results for in vitro multiplication and rooting, respectively, of 'Woodard' blueberry.

Keywords: Micropropagation; Vaccinium spp.; Cellulose acetate filters; Plant growth regulators.

\section{Resumen}

El objetivo de este estudio fue evaluar el efecto de la calidad de la luz y de los reguladores de crecimiento 2isopentenil adenina (2-ip) y ácido indol 3-butírico (AIB) sobre la multiplicación y enraizamiento in vitro del arándano 'Woodard'. Los experimentos se organizaron en un diseño completamente aleatorizado, con tres niveles de calidad de luz (rojo, azul y blanco) y dos niveles de regulador del crecimiento vegetal (presencia o ausencia de $100 \mathrm{mg} \mathrm{L}-12$-ip o $0.5 \mathrm{mg} \mathrm{L}-1 \mathrm{AIB}$, en los experimentos de multiplicación y enraizamiento, respectivamente). Los parámetros evaluados en ambos experimentos fueron tasa de supervivencia (\%), número de brotes por explante, el largo de los brotes $(\mathrm{cm})$; número de hojas por explante y área foliar $(\mathrm{cm} 2)$. En el experimento de multiplicación también se cuantificó el contenido de pigmentos fotosintéticos [clorofila (chl) ay chl b, chl a + b y carotenoides] y en el ensayo de enraizamiento el número y largo de la raíz. Los resultados muestran que la presencia de 2-ip en asociación con la luz blanca da como resultado brotes más largos, así como un mayor número de brotes y hojas. La mayor superficie foliar se observó con luz blanca. El número y largo de la raíz fueron mayores en presencia de AIB en el medio. La asociación de luz fluorescente blanca y la presencia de 2-isopentenil adenina (2-ip) o ácido indol 3-butírico (IBA) en el medio proporciona los mejores resultados para la multiplicación y enraizamiento in vitro, respectivamente, del arándano 'Woodard'.

Palabras clave: Micropropagación; Vaccinium spp.; Filtros de acetato de celulosa; Reguladores del crecimiento vegetal.

\section{Introdução}

O mirtileiro, nativo da América do Norte, pertence à família Ericaceae e ao gênero Vaccinium, cresce naturalmente em algumas regiões da Europa e América do Norte, onde também é cultivado em grande escala (Medeiros et al., 2018). No Brasil, o cultivo dessa fruta é promissor, oferecendo grandes perspectivas para a geração de renda principalmente para a agricultura familiar, uma vez que essa cultura apresenta alta necessidade de mão-de-obra e baixa taxa de mecanização. Somase a isso o fato de que há boa aceitação por parte do mercado consumidor devido às suas propriedades nutracêuticas. Dentre os aspectos que limitam a expansão, destaca-se o lento crescimento das plantas e a difícil propagação de algumas cultivares, o que aumenta a custo das mudas (Yamamoto et al., 2017).

Na maioria das plantas frutíferas, a produção comercial de mudas é realizada por propagação vegetativa, que, além de proporcionar mudas de qualidade, fixa características agronômicas desejáveis de forma eficiente (Medeiros, 2018). Com o mirtileiro não é diferente, para tanto faz-se uso da técnica de micropropagação, a qual, além de produzir grande quantidade de plantas em curto período de tempo, permite a obtenção de mudas com qualidade fitossanitária, o que torna a micropropagação o principal método usado para produzir mudas de mirtileiro sem vírus para cultivo (Murashige, 1974; Chen et al. 2018; Guo et al., 2019). Para o sucesso da propagação de culturas in vitro, o uso de reguladores de crescimento é de suma importância. Estes são adicionados ao meio de cultura em concentrações específicas e desempenham um papel fundamental no crescimento e na morfogênese em cultura de tecidos (Pierik, 1990; Flores et al., 1998).

O tipo de citocinina, fitorregulador cuja principal função está relacionada à divisão celular, e sua concentração são os principais fatores que influenciam o sucesso da multiplicação in vitro (Grattapaglia \& Machado, 1998). O 2-Isopenteniladenina (2ip) está entre as citocininas mais utilizadas e tem sido muito eficiente na multiplicação de partes aéreas e indução de gemas adventícias em diversas espécies (Hu \& Wang, 1983). Na fase de enraizamento in vitro, o tipo de meio de cultura, de auxina e suas concentrações são as variáveis que, em geral, alteram conforme a espécie e a cultivar. As auxinas compreendem uma 
grande família de substâncias que têm em comum a capacidade de promover o crescimento e a divisão celular em cultura de tecidos (Krikorian, 1991) e têm sido utilizadas na estimulação de raízes adventícias. Dentre elas, o Ácido Indolbutírico (AIB) tem sido usado por não causar fitotoxicidade aos explantes em uma larga faixa de concentração e ser eficiente em uma grande variedade despécies (Hartmann et al., 1997).

Além disso, a qualidade da luz, ou seja, o comprimento de onda específico, a densidade de fluxo de fótons e o fotoperíodo influenciam a morfogênese das plantas cultivadas in vitro (Lian et al., 2002; Singh et al., 2015; Souza et al., 2018). O mirtileiro é altamente influenciado pela intensidade da luz, embora os efeitos da qualidade desta não tenham ainda sido previamente elucidados. Fontes de luz artificiais comumente utilizadas para o cultivo de mirtileiro, bem como outras espécies de plantas são lâmpadas fluorescentes, lâmpadas de sódio de alta pressão lâmpadas de haletos metálicos, todas com baixa qualidade e comprimentos desnecessários para melhorar o crescimento e o desenvolvimento de plantas (Isutsa et al. 1994; Cao \& Hammerschlag, 2000; Gupta \& Jatothu, 2013).

Como alternativa às fontes de luz utilizadas tradicionalmente, foram introduzidos na propagação de plantas os diodos emissores de luz (LEDs), mais especificamente no cultivo de plantas micropropagadas, uma vez que, diferentes estudos mostram plantas in vitro mais vigorosas cultivadas sob condições de iluminação por LED (Moon et al. 2006; Lin et al. 2011; Hung et al. 2015; Batista et al. 2016; Ferreira et al. 2017; Batista et al., 2018). Estas vêm despertando o interesse de pesquisadores, que realizaram estudos sobre a aplicabilidade de diodos emissores de luz de amplo espectro (LEDs) para a micropropagação de espécies de plantas ornamentais (Miler et al., 2019), pereira (Lotfi et al., 2019) e bananeira (Musa spp.) (Bhaya \& Al-Razzaqsalim, 2019), os quais mostraram resultados promissores. Na busca pelo aprimoramento das informações sobre a qualidade de luz, ao invés do uso de LEDs como fonte de energia luminosa, um novo artifício para a modificação do espectro luminoso das luzes brancas frias pode ser adotado, mediante o uso de filtros coloridos de acetato celulose, do tipo Lee Filters (Walworth Ind. Estate, Andover, England). Estes, além de serem eficientes na modificação do espectro luminoso, possuem menor custo e podem ser instalados facilmente em uma sala de crescimento convencional dos laboratórios de cultura de tecidos.

Diante do exposto, este trabalho teve como objetivo avaliar os efeitos da qualidade de luz, associada ou não aos fitorreguladores 2-Isopenteniladenina (2ip) e ácido Indolbutírico (AIB) na multiplicação e no enraizamento, respectivamente, in vitro de mirtileiro 'Woodard'.

\section{Metodologia}

O experimento foi conduzido no Laboratório de Micropropagação de Plantas Frutíferas, do Departamento de Fitotecnia da Faculdade de Agronomia Eliseu Maciel (FAEM), e no Laboratório de Nutrição de Plantas do Departamento de Botânica do Instituto de Biologia, da Universidade Federal de Pelotas (UFPel), no município Capão do Leão, RS. Foram utilizadas plantas matrizes de mirtileiro 'Woodard' cultivadas in vitro pertencentes ao laboratório de Micropropagação de Plantas Frutíferas. Este trabalho foi dividido em dois experimentos: de multiplicação e enraizamento.

Para ambos os experimentos, o delineamento experimental utilizado foi o inteiramente casualizado, em esquema fatorial 3x2, com três níveis para o fator qualidade de luz e dois níveis para fitorregulador. Os níveis do primeiro fator, para ambos os experimentos, foram: luz azul, luz vermelha e luz branca. A variação no tipo de luz foi fornecida por meio do uso de filtros coloridos de acetato celulose, do tipo Lee Filters (Walworth Ind. Estate, Andover, England), com as seguintes especificações: azul (número 118 Light blue) com transmitância de 79 lm m-2 (64,2 nm de comprimento de onda), e vermelho (número 106 Primary red) com $26 \mathrm{~lm} \mathrm{m-2} \mathrm{(21,13} \mathrm{nm} \mathrm{de} \mathrm{comprimento} \mathrm{de} \mathrm{onda),} \mathrm{bem} \mathrm{como} \mathrm{de} \mathrm{lâmpada} \mathrm{fluorescente} \mathrm{branca}$ fria, com $299 \mathrm{~lm} \mathrm{~m}$-2. Os níveis do segundo fator foram presença e ausência de fitorregulador, utilizando-se para isto $100 \mathrm{mg}$ L-1 de 2-ip (2-isopenteniladenina) como fonte de citocinina no experimento de multiplicação e 0,5 mg L-1 de AIB (ácido 
indolbutírico), como fonte de auxina no experimento de enraizamento. As concentrações desses fitorreguladores foram definidas com base em experimentos preliminares. Foram utilizadas cinco repetições por tratamento, sendo cada uma destas constituída de um frasco com cinco explantes. Este é um experimento de natureza qualitativa x quantitativa (Pereira et al., 2018).

Em ambos os experimentos foram utilizados como explantes segmentos nodais com 2 gemas. O meio de cultura utilizado foi WPM (Wood Plant media - Lloyd e McCown, 1980), adicionado de sacarose (30 g L-1), mio-inositol (100 mg L1), 2-isopenteniladenina (2-IP) ou ácido indolbutírico (AIB), conforme o tratamento e ágar (6 g L-1). O pH foi ajustado para 5,0 antes da adição do ágar. O meio de cultura foi distribuído em frascos de vidro com capacidade para $200 \mathrm{~mL}$, contendo 30 $\mathrm{mL}$ de meio cada, autoclavado à $120^{\circ} \mathrm{C}$ e $1,5 \mathrm{~atm}$ de pressão, por 20 minutos. Posteriormente, foi realizada a inoculação dos explantes no meio de cultura, em câmara de fluxo laminar para evitar contaminação. Em seguida, estes foram transferidos para sala de crescimento com temperatura de $25 \pm 2{ }^{\circ} \mathrm{C}$, fotoperíodo de 16 horas e densidade de fluxo de fótons de $27 \mu \mathrm{mol} \mathrm{m}-2 \mathrm{~s}-1$.

As variáveis analisadas no experimento de multiplicação foram: porcentagem de sobrevivência, número de brotações, comprimento da maior brotação $(\mathrm{cm})$ e da parte aérea $(\mathrm{cm})$, número de folhas (gemas) e taxa de multiplicação (números absolutos), onde a percentagem de sobrevivência foi obtida através da relação entre os explantes vivos e o total de explantes em cada repetição. Aos 60 dias após a implantação do experimento, foi realizada a contagem do número de brotações e de folhas, o comprimento das brotações e de parte aérea foi medido com uma régua. Posteriormente os explantes foram submetidos à análise de área foliar, extração e quantificação de pigmentos fotossintéticos (Clorofila a, Clorofila b, Clorofila total e Carotenoides).

A avaliação de área foliar foi realizada por um integrador de área foliar da marca LI-COR®, modelo LI 3100 . O processo de extração e quantificação dos pigmentos fotossintéticos (clorofila a, clorofila b, clorofila total e carotenoides) foi realizado posteriormente, onde a extração seguiu a metodologia proposta por Arnon (Arnon, 1945). Para tal, em sala escura para evitar a fotodegradação, amostras de aproximadamente $100 \mathrm{mg}$ de tecido foliar fresco foram maceradas em almofariz com auxílio de pistilo com acetona $80 \%$, onde após verter o conteúdo em eppendorf de 2,0 mL, foram levados para centrifugar a $3.000 \mathrm{rpm}$ por $10 \mathrm{~min}$. Completou-se o volume para $10 \mathrm{~mL}$ em tubo falcon com acetona $80 \%$. As absorbâncias para clorofila a, clorofila b e carotenoides foram lidas em espectrofotômetro a 663,2, 646,8 e 470, nm, respectivamente, sendo as leituras utilizadas em fórmulas, segundo Lichtenthaler (1987): Clorofila a $(\mathrm{Ca})=12.25 \mathrm{~A} 663,2-2.04 \mathrm{~A} 646,8$; Clorofila b $(\mathrm{Cb})=$ 21,50A646,8 - 4.19A663,2; Clorofila Total = 7.15A663,2 + 18.71A646,8; Carotenoides $($ xantofilas + carotenos $)($ CT $)=$ (1.000A470 - 1.82Ca - 85,02Cb) / 198. A partir dos valores obtidos para clorofilas, calculou-se a razão clorofila a/b. Os resultados foram corrigidos de acordo com o volume final do extrato e peso fresco utilizado. Essa correção foi realizada pela multiplicação do valor de $\mathrm{Ca}, \mathrm{Cb}$ e CT (obtidos pelas fórmulas anteriormente mencionadas) pelo volume do extrato (10 mL), e dividindo-se esse valor pela massa real da amostra, mensurada individualmente por repetição. A massa de tecido vegetal foi de aproximadamente $100 \mathrm{mg}$, mas há variações entre as amostras, razão pela qual é realizada essa correção. Os teores de clorofila $\mathrm{a}, \mathrm{b}$, total e carotenoides presentes no material vegetal foram expressos em $\mathrm{mg}$ g-1MF.

No segundo experimento, de enraizamento, foram avaliados a porcentagem de sobrevivência, número de brotações, comprimento da maior brotação $(\mathrm{cm})$, comprimento de parte aérea $\mathrm{cm}$ ), número de folhas (em números absolutos), número de raízes, porcentagem de enraizamento $(\%)$ e comprimento da maior raiz $(\mathrm{cm})$. As avaliações das variáveis porcentagem de sobrevivência, número de brotações, comprimento da maior brotação $(\mathrm{cm})$, comprimento de parte aérea (cm) e número de folhas (em números absolutos), foram realizadas de igual forma ao experimento de multiplicação e foi realizada a contagem do número de raízes, além da porcentagem de enraizamento que foi calculada a partir da relação do número de raízes e o total de raízes em cada repetição, bem como o comprimento da maior raiz, que foi medido com o auxílio de uma régua. As avaliações foram realizadas 60 dias após a entrada do material na sala de crescimento. 
As analises estatísticas foram realizadas utilizando o software R (R Core Team, 2017). Os dados foram analisados quanto a normalidade pelo teste de Shapiro-Wilk, homocedasticidade pelo teste de Hartley e a independência dos resíduos por meio de análise gráfica. Os dados expressos em porcentagem foram transformados em: arcsin [raiz quadrada ( +1$)$ ] e raiz quadrada $(n+1)$, respectivamente. Os dados foram submetidos a análise de variância (ANOVA) pelo teste F (p $\leq 0.05$ ), quando diferenças dignificando foram encontradas, os efeitos do tratamento foram comparados pelo teste de Tukey ( $\mathrm{p} \leq 0.05$ ).

\section{Resultados e Discussão}

Considerando-se o experimento de multiplicação, não houve efeito significativo da interação entre os fatores, bem como dos fatores principais, na porcentagem de sobrevivência e comprimento da maior brotação (Tabela 1). Para as variáveis número de brotações (Tabela 1) e número de folhas (Tabela 2) houve efeito significativo de 2ip, em que os maiores valores foram observados na presença do fitorregulador no meio de cultivo. As citocininas agem induzindo a quebra da dominância apical e proliferação de gemas axilares, promovendo o desenvolvimento da parte aérea (Silva et al., 2018), por isso foi possível observar os maiores valores na presença do referido regulador de crescimento. Ainda no trabalho realizado por Silva et al. (2018), estudando o efeito da citocinina 6-Benzilaminopurina (BAP) sobre o estabelecimento in vitro de segmentos nodais de Rosa sp., foi descrito que após 21 dias de cultivo, observaram maior tendência na ocorrência de brotações para todos os tratamentos que continham o regulador, o qual se manteve aos 30 dias de estabelecimento.

Tabela 1. Porcentagem de sobrevivência, número de brotações e comprimento da maior brotação de mirtileiro "Woodard" em função da qualidade de luz e presença $\left(100 \mathrm{mg} \mathrm{L}^{-1}\right)$ e ausência $\left(0 \mathrm{mg} \mathrm{L}^{-1}\right)$ de 2-isopenteniladenina (2-IP).

\begin{tabular}{|c|c|c|c|}
\hline Tratamentos & Sobrevivência (\%) & N. Brotações & $\begin{array}{l}\text { Comp. maior brotação } \\
(\mathrm{cm})\end{array}$ \\
\hline \multicolumn{4}{|l|}{$\underline{\text { Filtro }}$} \\
\hline Azul & $96.7^{\mathrm{ns}}$ & $1.94^{\mathrm{ns}}$ & $1.64^{\mathrm{ns}}$ \\
\hline Vemelho & 96.7 & 2.10 & 1.69 \\
\hline Branco & 100.0 & 1.74 & 1.58 \\
\hline \multicolumn{4}{|l|}{2 ip } \\
\hline Com & $95.6^{\mathrm{ns}}$ & $2.71 \mathrm{a}$ & $1.60^{\mathrm{ns}}$ \\
\hline Sem & 100.0 & $1.14 \mathrm{~b}$ & 1.68 \\
\hline \multicolumn{4}{|l|}{$\underline{p}$} \\
\hline Filtro & 0.387 & 0.535 & 0.913 \\
\hline 2ip & 0.061 & $<0.001$ & 0.703 \\
\hline Filtro x 2ip & 0.387 & 0.530 & 0.873 \\
\hline
\end{tabular}

(1) Médias seguidas de letras iguais, minúsculas nas colunas e maiúsculas nas linhas, não diferem pelo teste de Tukey, a 5\% de probabilidade. ns: não significante.

Fonte: Mateus da Silveira Pasa.

A variável área foliar foi afetada significativamente por ambos os fatores, mas não houve interação entre eles. A utilização do filtro branco resultou na maior área foliar, sendo a menor com o filtro vermelho. A área foliar também foi maior 
na ausência de 2ip no meio de cultivo (Tabela 2). O inverso ocorreu no experimento realizado por Lotfi et al. (2019), onde utilizaram a citocinina meta- topolina (m TR) e verificaram uma menor área foliar sob luz fluorescente branca. Isto pode provar que há diferenças entre espécies, ou até mesmo o tipo de citocinina utilizada pode ter sido o principal agente que causou as diferenças entre os experimentos. A escolha de uma citocinina e sua concentração depende das espécies e é influenciada pelo objetivo final que se deseja com tal cultura (Lotfi et al., 2019).

Tabela 2. Número de folhas, área foliar e comprimento de parte aérea de mirtileiro "Woodard" em função da qualidade de luz e presença $\left(100 \mathrm{mg} \mathrm{L}^{-1}\right)$ e ausência $\left(0 \mathrm{mg} \mathrm{L}^{-1}\right)$ de 2-isopenteniladenina (2-IP).

Tratamentos N. folhas Área foliar $\left(\mathrm{cm}^{-2}\right) \quad$ Comp. parte aérea $(\mathrm{cm})$

\begin{tabular}{|c|c|c|c|c|c|}
\hline \multirow[b]{2}{*}{$\underline{\text { Filtro }}$} & & & \multicolumn{2}{|l|}{ Com } & \multirow[t]{2}{*}{ Sem } \\
\hline & & & & & \\
\hline Azul & $15.72^{\mathrm{ns}}$ & $3.79 \mathrm{ab}$ & $0.65 \mathrm{~b}$ & & 0.78 \\
\hline Vemelho & 13.12 & $2.71 \mathrm{~b}$ & $2.03 \mathrm{aA}$ & & $0.65 \mathrm{~B}$ \\
\hline Branco & 18.03 & $5.19 \mathrm{a}$ & $2.18 \mathrm{aA}$ & & $0.69 \mathrm{~B}$ \\
\hline \multicolumn{6}{|l|}{$2 \mathrm{ip}$} \\
\hline Com & $22.42 \mathrm{a}$ & $3.14 \mathrm{~b}$ & & - & \\
\hline Sem & $8.82 \mathrm{~b}$ & $4.65 \mathrm{a}$ & & - & \\
\hline \multicolumn{6}{|l|}{$p$} \\
\hline Filtro & 0.234 & 0.032 & & 0.005 & \\
\hline 2ip & $<0.001$ & 0.043 & & $<0.001$ & \\
\hline Filtro x 2ip & 0.759 & 0.601 & & 0.001 & \\
\hline
\end{tabular}

(1) Médias seguidas de letras iguais, minúsculas nas colunas e maiúsculas nas linhas, não diferem pelo teste de Tukey, a 5\% de probabilidade. ns: não significante.

Fonte: Mateus da Silveira Pasa.

Interação significativa entre os fatores foi observada para a variável comprimento da parte aérea. Na presença de $2 \mathrm{ip}$, os maiores valores foram obtidos com os filtros branco e vermelho, enquanto que na ausência de 2ip não foram observadas diferenças entre os filtros. Considerando-se os níveis de 2ip em cada nível de filtro, maior comprimento da parte aérea foi obtido na presença de 2 ip para os filtros branco e vermelho, enquanto que no filtro azul não foram observadas diferenças (Table 2). Pasa et al. (2012), ao trabalharem com amoreira preta 'Xavante' observaram o contrário na presença de citocinina benzilaminopurina (BAP) visto que os explantes submetidos à luz azul foram os que apresentaram comprimento superior das brotações e na ausência deste fitorregulador, destacou-se a luz vermelha. Essas diferenças verificadas entre os resultados provavelmente indiquem a existência de respostas diferenciadas entre espécies e até mesmo entre cultivares com relação à absorção de luz.

Com relação aos pigmentos clorofilas e carotenoides, houve interação entre os fatores. Considerando o fator 2ip em cada nível de filtro, observou-se que os teores de clorofila a, clorofila b, clorofila total e de carotenoides foram superiores na 
ausência de 2ip nos filtros vermelho e branco. Considerando os níveis de filtro na presença de 2ip, a maior quantidade de clorofila b, total e carotenoides foi observada com o filtro azul (Tabela 3). Em Vaccinium corymbosum, o uso do LED azul promoveu o acúmulo de clorofila, enquanto o LED vermelho reverteu esse efeito (Hung et al. 2016). Como os espectros azul e vermelho são necessários para a síntese de clorofila e carotenoides, a combinação de ambos os espectros em uma proporção adequada seria ideal (Gupta e Jatothu, 2013), no intuito de obter maiores valores de componentes fotossintéticos que são essenciais para o crescimento e desenvolvimento das plantas. No entanto, vale ressaltar que nestes resultados referentes aos pigmentos, a presença ou ausência de fitorregulador foi decisiva, assim como no experimento de Gentile et al. (2017), onde estes verificaram maior teor de clorofila a e a proporção de clorofila a/b na presença de citocinina. O conteúdo total de carotenoides foi menor na presença deste regulador de crescimento o que vai de encontro com o resultado obtido neste trabalho.

Tabela 3. Clorofila a, clorofila b, clorofila total, razão clorofila a/b e carotenoides totais de mirtileiro "Woodard" em função da qualidade de luz e presença $\left(100 \mathrm{mg} \mathrm{L}^{-1}\right)$ e ausência $\left(0 \mathrm{mg} \mathrm{L}^{-1}\right)$ de 2-isopenteniladenina (2-IP).

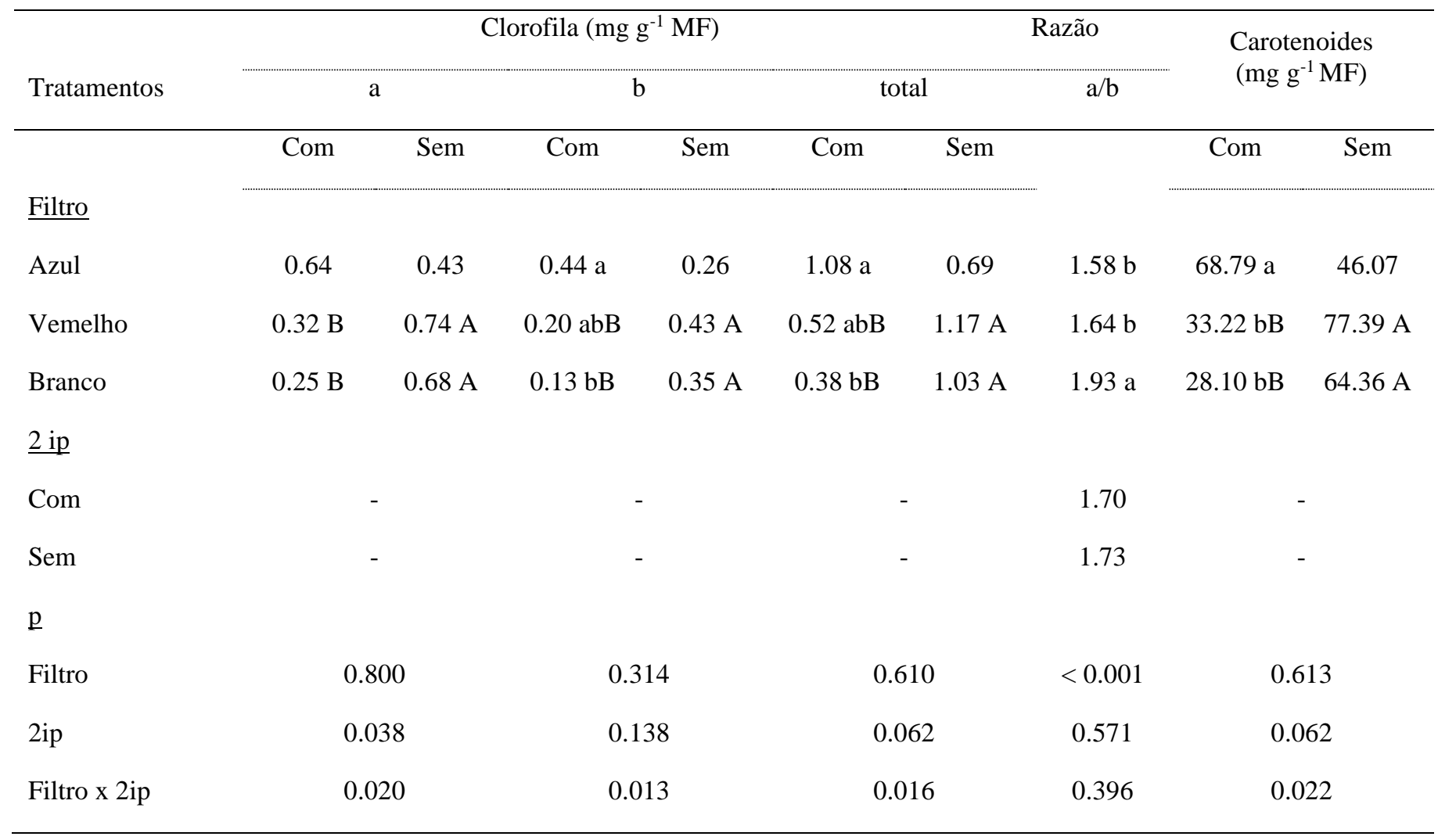

(1) Médias seguidas de letras iguais, minúsculas nas colunas e maiúsculas nas linhas, não diferem pelo teste de Tukey, a 5\% de probabilidade.

Fonte: Mateus da Silveira Pasa.

$\mathrm{Na}$ relação clorofila a/b, foi observado efeito apenas do fator principal filtro, em que o maior valor foi observado com o filtro branco (Tabela 3). Pode-se verificar nestes pigmentos fotossintéticos que os maiores valores foram constatados na ausência do fitorregulador (Tabela 3), fato que evidencia que a qualidade de luz influenciou no resultado, destacando os filtros de luz vermelho e branco. Em um experimento realizado por Lotfi et al. (2019) foi observado maior acúmulo de carotenoides sob LEDs vermelho distante e vermelho, seguido pela fluorescente, o que vai de encontro aos dados obtidos neste experimento.

Considerando-se o experimento de enraizamento, não foi verificada interação significativa entre os fatores para as variáveis porcentagem de sobrevivência, número de raízes, comprimento da maior raiz e número de brotações. Porém, houve 
efeito dos fatores principais para essas vairáveis, exceto para a porcentagem de sobrevivência (Tabela 4). O número de raízes foi influenciado significativamente por ambos os fatores, sendo que a utilização do filtro branco, bem como a presença de AIB, resultou em maior número. Já o comprimento da maior raiz não apresentou diferenças significativas quando na presença de filtros de luz, no entanto, foi maior na presença de AIB. Em estudo realizado por Hung et al. (2016), verificaram que o enraizamento in vitro de plantas de mirtileiro requer o tratamento de uma auxina como AIB (ácido indol-3-butírico), além disso as características de enraizamento são pouco afetadas pelos tratamentos com LED.

Tabela 4. Porcentagem de sobrevivência, número de raízes, comprimento da maior raiz e número de brotações de mirtileiro "Woodard" em função da qualidade de luz e presença $\left(0,5 \mathrm{mg} \mathrm{L}^{-1}\right)$ e ausência $\left(0 \mathrm{mg} \mathrm{L}^{-1}\right)$ de ácido indolbutírico (AIB).

\begin{tabular}{lcccc}
\hline Tratamentos & $\begin{array}{c}\text { Sobrevivência } \\
(\%)\end{array}$ & $\mathrm{N}^{\circ}$ Raízes & $\begin{array}{c}\text { Comp. maior } \\
\text { raiz }(\mathrm{cm})\end{array}$ & $\mathrm{N}^{\mathrm{o}}$ Brotações \\
& & & \\
\hline
\end{tabular}

\section{$\underline{\text { Filtro }}$}

\begin{tabular}{lcccc} 
Azul & $100.0^{\mathrm{ns}}$ & $0.68 \mathrm{~b}$ & $0.22^{\mathrm{ns}}$ & $1.30 \mathrm{ab}$ \\
Vemelho & 100.0 & $1.51 \mathrm{~b}$ & 0.44 & $0.90 \mathrm{~b}$ \\
Branco & 97.5 & $3.04 \mathrm{a}$ & 0.54 & $1.59 \mathrm{a}$ \\
$\underline{\text { AIB }}$ & & & & \\
Com & $98.3^{\mathrm{ns}}$ & $2.36 \mathrm{a}$ & $0.64 \mathrm{a}$ & 1.36 \\
Sem & 100.0 & $1.13 \mathrm{~b}$ & $0.16 \mathrm{~b}$ & 1.16 \\
$\underline{p}$ & & & & \\
Filtro & 0.387 & 0.001 & 0.199 & 0.005 \\
AIB & 0.331 & 0.010 & 0.004 & 0.197 \\
Filtro x AIB & 0.387 & 0.052 & 0.813 & 0.541 \\
\hline
\end{tabular}

(1) Médias seguidas de letras iguais, minúsculas nas colunas e maiúsculas nas linhas, não diferem pelo teste de Tukey, a 5\% de probabilidade. ns: não significante.

Fonte: Mateus da Silveira Pasa.

Com relação ao número de brotações, não foi observado efeito significativo do fator AIB. No entanto, foram verificadas diferenças significativas para o fator filtro de luz, onde o filtro branco apresentou maior número de brotações que o filtro vermelho (Tabela 4). Estudos realizados e suportados por uma patente demonstram que comprimentos de onda de 400 a $500 \mathrm{~nm}$ (luz azul) podem controlar o crescimento fototrópico, a extensão das folhas, o alongamento da parte aérea e o acúmulo de antocianinas (Folta et al., 2014; Hung et al., 2016), isso explica o fato de que na presença do filtro de luz azul, assim como no branco, houve um maior número de brotações. Além disso, no estudo de Hung et al. (2016), também foi verificado maior número de plantas a partir de explantes cultivados na presença de auxina com luz fluorescente, resultando na produção de 26,75 plantas/explante. No referido trabalho o tratamento com LED colorido foi, de maneira geral, ideal e superior às lâmpadas fluorescentes, na propagação clonal do genótipo de mirtilo rabbiteye. Portanto, recomendou-se que os LEDs sejam usados para micropropagação uma vez que estes são eficientes para substituir lâmpadas fluorescentes convencionais. No presente trabalho 
apresentamos mais uma alternativa viável, que é a utilização dos filtros coloridos de acetato celulose, do tipo Lee Filters (Walworth Ind. Estate, Andover, England), estes além de terem um ótimo custo-benefício propiciam a modificação do espectro luminoso com qualidade.

Ainda no experimento de enraizamento, com relação às variáveis comprimento de brotações, comprimento de parte aérea e número de folhas, não foi observado efeito significativo da interação entre os fatores, apenas dos fatores principais. O comprimento da maior brotação apresentou maiores valores na presença de AIB, enquanto que para o fator filtro de luz não foram observadas diferenças significativas (Tabela 5). Isso demonstra que as auxinas promovem divisão, alongamento e diferenciação celular, além de serem responsáveis pela dominância apical (Taiz et al., 2017), o que possibilitou o crescimento das brotações. Já na variável comprimento de parte aérea, apenas os filtros de luz diferenciaram significativamente, onde o filtro de luz vermelho foi superior ao azul. De acordo com Rocha et al. (2010), o espectro da luz vermelha está próximo dos picos máximos de absorção de luz dos clorófilos e fitocromos; por esse motivo, a luz vermelha é importante para o aparato fotossintético e o acúmulo de amido, melhorando o desenvolvimento das gemas e consequentemente da parte aérea.

Tabela 5. Comprimento da maior brotação, Comprimento de parte aérea, Número de folhas e área foliar de mirtileiro "Woodard” em função da qualidade de luz e presença (0,5mg L-1) e ausência (0 mg L-1) de ácido indolbutírico (AIB).

\begin{tabular}{cccc}
\hline Tratamentos & $\begin{array}{c}\text { Comp. maior brot } \\
(\mathrm{cm})\end{array}$ & $\begin{array}{c}\text { Comp. parte } \\
\text { aérea }(\mathrm{cm})\end{array}$ & N. folhas
\end{tabular}

\begin{tabular}{|c|c|c|c|c|c|c|}
\hline & & & & Com & & Sem \\
\hline \multicolumn{7}{|l|}{$\underline{\text { Filtro }}$} \\
\hline Azul & $1.76^{\mathrm{ns}}$ & $1.00 \mathrm{~b}$ & $11.40 \mathrm{~b}$ & $4.97 \mathrm{~b}$ & & $3.28 \mathrm{~b}$ \\
\hline Vemelho & 1.92 & $1.63 \mathrm{a}$ & $10.35 \mathrm{~b}$ & $9.74 \mathrm{aA}$ & & $2.77 \mathrm{bB}$ \\
\hline Branco & 2.07 & $1.08 \mathrm{ab}$ & $16.52 \mathrm{a}$ & $2.41 \mathrm{cB}$ & & $6.90 \mathrm{aA}$ \\
\hline \multicolumn{7}{|l|}{$\underline{\mathrm{AIB}}$} \\
\hline Com & $2.49 \mathrm{a}$ & $1.13^{\mathrm{ns}}$ & $14.37 \mathrm{a}$ & & - & \\
\hline Sem & $1.34 \mathrm{~b}$ & 1.34 & $11.15 \mathrm{~b}$ & & - & \\
\hline \multicolumn{7}{|l|}{$\underline{p}$} \\
\hline Filtro & 0.656 & 0.018 & $<0.001$ & & 0.006 & \\
\hline AIB & 0.001 & 0.254 & 0.001 & & 0.011 & \\
\hline Filtro x AIB & 0.306 & 0.220 & 0.363 & & 0.000 & \\
\hline
\end{tabular}

Quanto ao número de folhas, houve efeito significativo de ambos os fatores. Considerando o fator filtro de luz, o maior número de folhas foi observado com o filtro branco, enquanto que para o fator AIB, o maior valor foi obtido na presença do fitorregulador (Tabela 4). Com relação a área foliar, foi observada interação significativa entre os fatores. Utilizando-se os níveis de filtro na presença de AIB, observou-se a maior área foliar com o filtro vermelho, e menor com o branco. Enquanto que ausência de AIB, o filtro de luz branco apresentou maior área foliar que os demais tratamentos. Com relação ao fator AIB 
em cada nível de filtro, foram observadas diferenças nos filtros vermelho e branco, em que a maior área foliar com o filtro vermelho foi observada na presença de AIB, sendo o inverso observado com o filtro branco (Tabela 5).

Desta forma, a presença de ácido indol-3-butírico (AIB) foi fundamental para as variáveis número de folhas e área foliar. Conforme observado para a variável comprimento de parte aérea, as auxinas são responsáveis pela promoção da divisão, alongamento e diferenciação celular, isso faz com que elas atuem também no desenvolvimento de parte aérea e não somente no enraizamento que é a sua principal e mais conhecida função. Os efeitos da qualidade da luz em plantas in vitro variam amplamente, considerando que a luz azul é útil para a síntese de clorofila, maturação de cloroplastos e abertura estomática, enquanto que a vermelha é necessária para o crescimento das folhas e o acúmulo de carboidratos (Lotfi et al., 2019), por isso o maior desenvolvimento de área foliar na presença de filtro de luz vermelho e menor no azul e no branco na ausência do regulador de crescimento.

Os resultados revelados neste trabalho contribuíram significativamente para aumentar o conhecimento relacionado a micropropagação e desenvolvimento vegetativo de mudas de mirtileiro da cultivar 'Woodard' (Vaccinium Spp). Além disso, é evidente que o uso de fitorreguladores proporciona melhores resultados quando adicionados ao meio de cultura e os espectros de luz obtidos com os filtros podem ocasionar mudanças na morfologia da planta, bem como no conteúdo de produtos fotossintéticos.

\section{Conclusão}

A presença de 2-Isopenteniladenina (2ip), bem como a presença de Ácido Indolbutírico (AIB), associado a luz branca fluorescente proporciona melhores resultados para a multiplicação e enraizamento in vitro de mirtileiro 'Woodard' respectivamente.

Os resultados deste trabalho abrem espaço para que novos experimentos sejam realizados a fim de confirmar os efeitos que a qualidade de luz pode proporcionar. É sabido que os espectros de luz obtidos com os filtros possuem comprimentos de onda inferior ao que se deseja para ocasionar mudanças na morfologia da planta, logo, para futuros trabalhos seria interessante o uso de LEDs no intuito de comparar resultados com a utilização de filtros de luz, quantificando tanto os pigmentos fotossintéticos, como também verificando as modificações que podem causar na morfologia da planta.

\section{Referências}

Arnos, D. J. (1945). Cooper enzymes in isolated chloroplast: Polyphenoloxidase in Beta vulgaris. Plant Physiology, $24,1-15$.

Batista, D. S., Castro, K. M., Silva, A. R., Teixeira, M. L., Sales, T. A., Soares, L. I., Cardoso, M. G., Santos, M. O., Viccini, L. F., \& Otoni, W. C. (2016). Light quality affects in vitro growth and essential oil profile in Lippia alba (Verbenaceae). In Vitro Cell Dev Biol-Plant 52:276-282.

Batista, D. S., Felipe, S. H. S., Silva, T. D., De Castro, K. M., Mamedes-Rodrigues, T. C., Miranda, N. A. A., Ríos-Ríos, A. M., Faria, D. V., Fortini, E. A., Chagas, K., Silva, G. T., Xavier, A., Arencibia, A. D., \& Otoni, W. C. (2018) Light quality in plant tissue culture: does it matter? In Vitro Cellular \& Developmental Biology-Plant, 54(3), 195-215.

Bhaya, M. H. M. \& Al-Razzaqsalim, S. N. (2019). Impacts os plant growth regulators and light quality on banana (Musa SPP) micropropagation. Plant Archives, 19(1), 1379-1385.

Cao, X. \& Hammerschlag, F. A. (2000). Improved shoot organogenesis from leaf explants of highbush blueberry. HortScience, 35(5), 945-947.

Chen, H. Y., Liu, J., Pan, C., Yu, J. W., \& Wang, Q. C. (2018). In vitro regeneration of adventitious buds from leaf explants and their subsequent cryopreservation in highbush blueberry. Plant Cell, Tissue and Organ Culture (PCTOC), 134(2), 193-204.

Ferreira, L. T., De Araújo Silva, M. M., Ulisses, C., Camara, T. R., \& Willadino, L. (2017). Using LED lighting in somatic embryogenesis and micropropagation of an elite sugarcane variety and its effect on redox metabolism during acclimatization. Plant Cell Tissue Organ Cult. 128:211-221.

Flores, R., Stefanello, S., Franco, E.; \& Mantovani, N. (1998). Regeneração in vitro de espinheira-santa (Maytenus ilicifolia Mart.). Revista Brasileira de Agrociência, 4(3), 201-205.

Folta, K. M., Clark, D. G., \& Colquhoun, T. A. (2014). Modulação leve de plantas e partes de plantas. Fundação de Pesquisa da Universidade da Flórida, Inc., Patente \# WO2014085626 A1. 
Gentile, A., Frattarelli, A., Nota, P., Condello, E., \& Carboni, E. (2017). The aromatic cytokinin meta-topolin promotes in vitro propagation, shoot quality and micrografting in Corylus coluna L. Plant Cell, Tissue and Organ Culture (PCTOC), 128(3), 693-703.

Guo, Y. X., Zhao, Y. Y., Zhang, M., \& Zhang, L. Y. (2019). Desenvolvimento de um novo sistema de cultivo de enraizamento in vitro para micropropagação de mudas de mirtilo (Vaccinium corymbosum). Plant Cell, Tissue and Organ Culture (PCTOC). 139 (3), 615-620.

Grattapaglia, D. \& Machado, M. A. (1998). Micropropagação. In: Torres, A. C.; Caldas, L. S.; \& Buso, J. A. Cultura de tecidos e transformação genética de plantas (Vol. 1). Embrapa-SPI: Embrapa-CNPH. 1, 183-260.

Gupta, S. D. \& Jatothu, B. (2013). Fundamentos e aplicações de díodos emissores de luz (LEDs) no crescimento de plantas in vitro e morfo-Gênesis. Planta Biotechnol Rep 7:211-220.

Hartmann, H. T.; Kester, D. E.; Davies, F. T.; \& Geneve, R. L. (1997). Plant propagation: principles and practices. (6a ed.), Prentice Hall. 549-622.

Hu, C. Y. \& Wang, P. J. (1983). Meristem, shoot tip and bud culture. In: Evans, D. A.; Sharp, W. R.; Ammirato, P. V.; \& Yamada, Y. (Eds.). Handbook of plant cell culture: techniques for propagation and breeding. New York: Macmillan. 117-227.

Hung, C. D., Hong, C. H., Jung, H. B., Kim, S. K., Van Ket, N., Nam, M. W., Choi, D. H., \& Lee, H. I. (2015). Growth and morphogenesis of encapsulated strawberry shoot tips under mixed LEDs. Sci Hortic. 194:194-200.

Hung, C. D., Hong, C. H., Kim, S. K., Lee, K. H., Park, J. Y., Dung, C. D., Nam, M. W., Choi, D. H., \& Lee, H. I. (2016). In vitro proliferation and ex vitro rooting of microshoots of commercially important rabbiteye blueberry (Vaccinium ashei Reade) using spectral lights. Sci Hortic. 211:248-254.

Isutsa, D. K, Pritts, M. P, \& Mudge, K. W. (1994). Rápida propagação de mirtilo plantas usando o enraizamento in vitro e ex- acclima controlada de micropropagules tization. Horticulture Science. 29, 1124-1126.

Krikorian, A. D. (1991). Medios de cultivo: generalidades, composición y preparación. In: Roca, W. R.; \& Mroginski, L. A. Cultivo de tejidos en la agricultura: fundamentos y aplicaciones. Cali, Colombia: Centro Internacional de Agricultura Tropical. 41-78.

Lian, M. L.; Murthy, H. N.; \& Paek, K. Y. (2002). Effects of light emitting diodes (LEDs) on the in vitro induction and growth of bulblets of Lilium oriental hybrid 'Pesaro'. Scientia Horticulturae, Amsterdam, 94, 365- 370.

Lin, Y., Li, J., Li, B., He, T., \& Chun, Z. (2011). Effects of light quality on growth and development of protocorm-like bodies of Dendrobium officinale in vitro. Plant Cell Tissue Organ Cult 105:329-335.

Lichtenthaler, H. K. (1987). Chlorophylls and carotenoids: Pigments of photosynthetic biomembranes. Methods in enzimology, 148, 350-382.

Lotfi, M., Mars, M., \& Werbrouck, S. (2019). Optimizing pear micropropagation and rooting with light emitting diodes and trans-cinnamic acid. Plant Growth Regulation, 88(2), 173-180.

Lloydl, G., \& McCown, B. (1980). Commercially-feasible micropropagation of mountain laurel, Kalmia latifolia, by use of shoot-tip culture. International Plant Propagation Society Proceedings, Washington, 30, 421-427.

Medeiros, J. G. S., Biasi, L. A., Bona, C. M. D., \& Cuquel, F. L. (2018). Fenologia, produção e qualidade de mirtilos produzidos em clima subtropical úmido. Revista Brasileira de Fruticultura, 40(3).

Miler, N., Kulus, D., Wozny, A., Rymars, D., Hajzer, M., Wierzbowski, Nelke, R., K., \& Szeffs, L. (2019). Application of wide-spectrum light-emitting diodes in micropropagation of popular ornamental plant species: a study on plant quality and cost reduction. In Vitro Cellular \& Developmental Biology-Plant, 55(1), 99-108.

Moon, H. K., Park, S. Y., Kim, Y. W., \& Kim, C. S. (2006). Growth of Tsuru-rindo (Tripterospermum japonicum) cultured in vitro under various sources of light-emitting diode (LED) irradiation. J Plant Biol 149: 174-179.

Murashige T. (1974). Propagação de plantas através de culturas de tecidos. Annu Rev Plant Physiol 25 (1): 135-166.

Pasa, M. D. S., Carvalho, G. L., Schuch, M. W., Schmitz, J. D., Torchelsen, M. M., Nickel, G. K., \& Camargo, S. S. (2012). Qualidade de luz e fitorreguladores na multiplicação e enraizamento in vitro da amoreira-preta 'Xavante'. Ciência Rural, 42(8).

Pereira A. S., Shitsuka, D. M., Parreira, F. J., \& Shitsuka, R. (2018). Metodologia da pesquisa científica. UFSM. https://repositorio.ufsm.br/bitstream/handle/1/15824/Lic_Computacao_Metodologia-Pesquisa-Cientifica.pdf?sequence=1.

Pierik, R. L. M. (1990). Cultivo in vitro de las plantas superiores. Ediciones Mudi-Prensa. 326p.

R Core Team. R: A language and environment for statistical computing. (2017). R Foundation for Statistical Computing. R Core Team, Vienna, Austria, URL $<$ http://www.R-project.org/>.

Rocha, P. S. G. D., Oliveira, R. P. D., Scivittaro, W. B., \& Santos, U. L. D. (2010). Diodos emissores de luz e concentrações de BAP na multiplicação in vitro de morangueiro. Ciência Rural, 40(9), 1922-1928.

Silva, J. P., Costa, M. K. C., De Araújo, M. R. S., Araújo, K. S., Da Silva, A. C. M., Dalla Costa, T. P., Oliveira, P. C., \& De Freitas Sia, E. (2018). Efeito da citocinina 6-benzilaminopurina (BAP) sobre o estabelecimento in vitro de segmentos nodais de Rosa sp. Revista Agroecossistemas, 9(2), 370-380.

Singh, D., Basu, C., Wollweber, M. N., \& Roth, B. (2015). LEDs for energy efficient greenhouse lighting. Renewable and Sustainable Energy Reviews.49:139-47. 
Research, Society and Development, v. 10, n. 2, e48510212790, 2021

(CC BY 4.0) | ISSN 2525-3409 | DOI: http://dx.doi.org/10.33448/rsd-v10i2.12790

Souza, D. M. S. C., Xavier, A., Otoni, W. C., Miranda, N. A., \& Maggioni, J. H. (2018). light quality in the in vitro introduction of Corymbia hybrid clones. Revista Árvore, 42(6).

Taiz, L., Zeiger, E., Moller, I., \& Murphy, A. (2017). Fisiologia e desenvolvimento vegetal. (6a ed.), Artmed. 888 p.

Yamamoto, L. Y., De Assis, A. M., Koyama, R., Borges, W. F. S., Favetta, V., Antunes, L. E. C., \& Roberto, S. R. (2017). Substratos e concentrações de AIB no enraizamento de estacas herbáceas de mirtilo 'Woodard'. Ciência da agronomia e biotecnologia, 3 (2), 113. 